\title{
A Comparative Study of $\mathrm{AlCl}_{3}$ and $\mathrm{FeCl}_{2}$-Modified $\mathrm{TiCl}_{4} / \mathrm{MgCl}_{2} / \mathrm{THF}$ Catalytic System in the Presence of Hydrogen for Ethylene Polymerization
}

\author{
Thanyathorn Niyomthai, Aniroot Ratchadaphet, \\ Bunjerd Jongsomjit, and Piyasan Praserthdam

\begin{abstract}
Center of Excellence on Catalysis and Catalytic Reaction Engineering, Department of Chemical Engineering,
\end{abstract} \\ Faculty of Engineering, Chulalongkorn University, Bangkok 10330, Thailand
}

Correspondence should be addressed to Piyasan Praserthdam; piyasan.p@chula.ac.th

Received 28 April 2016; Revised 6 July 2016; Accepted 14 July 2016

Academic Editor: Atsushi Sudo

Copyright (C) 2016 Thanyathorn Niyomthai et al. This is an open access article distributed under the Creative Commons Attribution License, which permits unrestricted use, distribution, and reproduction in any medium, provided the original work is properly cited.

\begin{abstract}
Ethylene homopolymerization over $\mathrm{TiCl}_{4} / \mathrm{MgCl}_{2} / \mathrm{THF}$ catalysts modified with different metal halide additives $\left(\mathrm{AlCl}_{3}\right.$ and $\left.\mathrm{FeCl}{ }_{2}\right)$ with and without hydrogen was investigated based on catalytic activity and polymer properties. Lewis acid modification can improve activity because it can remove the remaining THF in the final catalyst, which can poison the catalyst active sites via the ring-opening of THF that was confirmed by XRD measurements. Moreover, the activity enhancement was due to the formation of acidic sites by modifying the catalysts with Lewis acids. Thus, $\mathrm{FeCl}_{2}$ doped catalyst ( $\mathrm{Fe}-\mathrm{THF}$ ) exhibited the highest activity followed by $\mathrm{AlCl}_{3}$ doped catalyst (Al-THF) and undoped catalyst (None-THF). In $\mathrm{H}_{2} / \mathrm{C}_{2} \mathrm{H}_{4}$ molar ratio of 0.08 , Fe-THF showed a better hydrogen response than Al-THF due to more titanium cluster distribution. Fe-THF is considered to have more clustered Ti species than AlTHF. As a consequence, it led us to obtain more possible chances to precede chain transfer reaction by hydrogen. The molecular weight, melting temperature, and crystallinity of obtained polymers were investigated by GPC and DSC measurement, respectively.
\end{abstract}

\section{Introduction}

The present generation of heterogeneous catalytic systems for polyolefin production based on $\mathrm{TiCl}_{4} / \mathrm{MgCl}_{2}$ supported catalyst is referred to Ziegler-Natta $(\mathrm{ZN})$ catalyst. It is one of the most advanced industrial and academic applications of catalysis. One of the important steps to create the highly active $\mathrm{ZN}$ catalyst is the preparation method of the precatalyst prior to the activation with alkylaluminum [1]. Lewis base, normally an alcohol likes ethanol or an ether likes tetrahydrofuran (THF) [1-3], plays an important role in creating bimetallic complexes with magnesium dichloride [3, 4]. Even though ethanol is more preferable choice as Lewis base, there are still many researches employing THF in the process of catalyst preparation. This is due to its easiness to prepare, which leads to the lower in cost. It also provides good hydrogen response and the moderate activity and increases the molecular weight of polymer [4-6]. Besides, Sobota [7] revealed that THF is the most mature as a selectivity control agent in ethylene polymerization. Therefore, THF complexes of $\mathrm{MgCl}_{2}$ and $\mathrm{TiCl}_{x}$ are frequently employed as the precursors. Another important factor that industries are concerned with is controlling of the molecular weight distribution of obtained polymers because it affects the final mechanical and processing properties of the polymer [8-11]. Polymer having short chains provides good processability, while polymer having high molecular weight fraction provides good mechanical properties. Hence, polymers having both short and long chains are required to produce polymers with a broad molecular weight distribution [12]. However, narrow or board molecular weight distribution depends on the desired application. As it is widely noticed, hydrogen is the key agent usually used to control molecular weight of polymer. Effect of hydrogen on activity is complicated to forecast because it depends on several factors such as type of catalyst system, monomer, donor systems, and polymerization conditions [13]. For example, hydrogen typically decreases activity in ethylene polymerization but increases in propylene 
TABLE 1: Abbreviation of the prepared catalysts.

\begin{tabular}{lc}
\hline Catalyst abbreviation & Component \\
\hline None-THF & $\mathrm{TiCl}_{4} / \mathrm{MgCl}_{2} / \mathrm{THF}$ \\
Al-THF & $\mathrm{TiCl}_{4} / \mathrm{AlCl}_{3} / \mathrm{MgCl}_{2} / \mathrm{THF}$ \\
Fe-THF & $\mathrm{TiCl}_{4} / \mathrm{FeCl}_{2} / \mathrm{MgCl}_{2} / \mathrm{THF}$ \\
\hline
\end{tabular}

polymerization for ZN catalyst [14]. Nevertheless, Hair and Hertl [15] revealed that the addition of a small amount of hydrogen can improve the activity in ethylene copolymerization. However, hydrogen effect on ZN catalyst systems is still ill-defined; however it is very significant. Thus, in this work, a comparative study of the $\mathrm{AlCl}_{3}$ and $\mathrm{FeCl}_{2}$ modified $\mathrm{TiCl}_{4}$ / $\mathrm{MgCl}_{2} / \mathrm{THF}$ catalytic system on the activity and polymer properties in the presence of hydrogen for ethylene polymerization was investigated.

\section{Experimental}

2.1. Materials. All materials and operation steps were conducted under nitrogen atmospheres using a standard glove box and Schlenk techniques. Polymerization grades of ethylene, hydrogen, and nitrogen were purchased from Linde Co., Ltd. Tetrahydrofuran (THF), aluminum trichloride $\left(\mathrm{AlCl}_{3}\right)$, and iron (II) chloride $\left(\mathrm{FeCl}_{2}\right)$ were purchased from SigmaAldrich and used without further purification. Titanium (IV) chloride $\left(\mathrm{TiCl}_{4}\right)$ was supplied from Merck. Anhydrous $\mathrm{MgCl}_{2}, \mathrm{n}$-hexane, and triethylaluminum (TEA) were donated by Thai Polyethylene Co., Ltd.

\subsection{Catalyst Preparation Methods}

2.2.1. $\mathrm{TiCl}_{4} / \mathrm{MgCl}_{2} / \mathrm{THF}$ Catalyst $[2,16]$. A mixture of $2 \mathrm{~g}$ of anhydrous $\mathrm{MgCl}_{2}$ (and Lewis acid if any) and $150 \mathrm{~mL}$ of tetrahydrofuran (THF) was added into the $500 \mathrm{~mL}$ threenecked round bottom flask equipped with magnetic stirrer. Then, $2 \mathrm{~mL}$ ( 0.87 mole) of $\mathrm{TiCl}_{4}$ was injected dropwise. The reaction was heated up to $70^{\circ} \mathrm{C}$ and held for $3 \mathrm{~h}$. After that, the reaction was cooled down to $40^{\circ} \mathrm{C}$. The washing steps were carried out for 7 times with n-hexane prior to obtain the None-THF catalyst.

$\mathrm{TiCl}_{4} / \mathrm{AlCl}_{3} / \mathrm{MgCl}_{2} / \mathrm{THF}$ and $\mathrm{TiCl}_{4} / \mathrm{FeCl}_{2} / \mathrm{MgCl}_{2} / \mathrm{THF}$ were denoted as Al-THF and Fe-THF, respectively, as shown in Table 1 . Lewis acid was directly added to $\mathrm{MgCl}_{2}$ in THF solution. All modified catalysts were synthesized by the same procedure as used for the preparation of the unmodified catalyst (None-THF) excepting for adding anhydrous $\mathrm{AlCl}_{3}$ for Al-THF and $\mathrm{FeCl}_{2}$ for Fe-THF, with $0.07 \mathrm{~mol} / \mathrm{mol}$ of Lewis acid/ $\mathrm{MgCl}_{2}$.

\subsection{Polymerization Reaction}

2.3.1. Effect of $\mathrm{H}_{2} / \mathrm{C}_{2} \mathrm{H}_{4}$ Molar Ratio. Ethylene polymerization was performed in $2 \mathrm{~L}$ autoclave reactor connected with n-hexane liquid feed line and nitrogen, hydrogen, ethylene gas feed lines. Purification of reactor and all feed lines were conducted by evacuation and purging with nitrogen many times. After that, $1 \mathrm{~L}$ of $\mathrm{n}$-hexane, triethylaluminum, and catalyst slurry $(\mathrm{Al} / \mathrm{Ti}$ molar ratio $=140)$ were introduced into the reactor. Then the reaction was heated up to $67^{\circ} \mathrm{C}$. At this temperature, 1 bar of nitrogen was filled and followed by the desired amount of hydrogen $\left(\mathrm{H}_{2} / \mathrm{C}_{2} \mathrm{H}_{4}\right.$ molar ratio $=$ $0,0.08,0.20$, and 0.30 ). Finally, the reactor was pressurized with the total pressure of 8 bars with ethylene at $75^{\circ} \mathrm{C}$. The polymerization temperature and time were $80^{\circ} \mathrm{C}$ and $1 \mathrm{~h}$, respectively. The obtained polymer was dried at room temperature overnight.

\subsection{Characterizations}

\subsubsection{Catalyst}

Inductively Coupled Plasma (ICP). Inductively coupled plasma optical emission spectrometer (ICP-OES optima 2100 DV from Perkin Elmer) was employed to determine element content in bulk. The catalyst sample was digested with $5 \mathrm{~mL}$ of hydrochloric acid and then diluted with DI water.

Fourier Transform Infrared Spectroscopy (FT-IR). The Fourier transforms infrared spectroscopy was applied with Nicolet 6700 FT-IR spectrometer with transmittance mode. The catalyst powder was prepared as a thin film on $\mathrm{NaCl}$ disk and kept under argon atmosphere during the analysis. The measurement was carried out in the range of scanning between 400 and $4000 \mathrm{~cm}^{-1}$ for 400 times.

X-Ray Diffraction (XRD). XRD was performed to identify phases and crystallinity of the catalyst and support samples using Bruker of D8 Advance. The sample was placed on holder under argon atmosphere to prevent air and moisture during the experiment. Diffraction patterns were recorded with the scanning speed of 0.3 second/step and step size 0.02 in the $2 \theta$ range of $10-80$ degrees.

Scanning Electron Microscopy (SEM) and Energy Dispersive XRay Spectroscopy (EDX). SEM was used to identify the morphologies of catalyst, while EDX was applied to investigate the elemental distribution. The SEM of Hitachi mode S-3400N was employed. The EDX was performed using Link Isis series 300 program.

\subsubsection{Polymer}

Gel Permeation Chromatography (GPC). Molecular weight and molecular weight distributions of polymers were determined by using a high temperature GPC (Waters $150^{\circ} \mathrm{C}$ ) equipped with a viscometric detector. The characterization was performed at $160^{\circ} \mathrm{C}$ and used 1,2,4-trichlorobenzene as a solvent.

Scanning Electron Microscopy (SEM). SEM was applied to determine the morphologies of the resultant polymers. The same equipment (as aforementioned) was carried out.

Differential Scanning Calorimetry (DSC). The melting temperature $\left(T_{m}\right)$ and percentage of crystallinity $\left(\chi_{c}\right)$ of polyethylene were determined by DSC-TGA with TA Instruments 
TABLE 2: The elemental composition of the prepared catalysts.

\begin{tabular}{|c|c|c|c|c|c|c|c|c|}
\hline \multirow{3}{*}{ Catalyst } & \multicolumn{4}{|c|}{ ICP measurement } & \multicolumn{4}{|c|}{ EDX measurement } \\
\hline & \multicolumn{3}{|c|}{ Element content $(\% \mathrm{wt})^{\mathrm{a}}$} & \multirow{2}{*}{$\begin{array}{c}\mathrm{Ti} / \mathrm{Mg} \\
(\mathrm{mol} / \mathrm{mol})\end{array}$} & \multicolumn{3}{|c|}{ Element content $(\% \mathrm{wt})^{\mathrm{c}}$} & \multirow{2}{*}{$\begin{array}{c}\mathrm{Ti} / \mathrm{Mg} \\
(\mathrm{mol} / \mathrm{mol})\end{array}$} \\
\hline & $\mathrm{Ti}$ & $\mathrm{Mg}$ & $\mathrm{M}^{\mathrm{b}}$ & & $\mathrm{Ti}$ & $\mathrm{Mg}$ & $\mathrm{M}^{\mathrm{b}}$ & \\
\hline None-THF & 4.07 & 6.87 & - & 0.30 & 6.52 & 24.32 & - & 0.14 \\
\hline Al-THF & 2.96 & 6.51 & 0.97 & 0.23 & 9.56 & 24.50 & 2.65 & 0.20 \\
\hline $\mathrm{Fe}-\mathrm{THF}$ & 4.61 & 5.87 & 1.58 & 0.40 & 9.27 & 19.08 & 11.79 & 0.25 \\
\hline
\end{tabular}

${ }^{\mathrm{a}}$ Determined by ICP.

${ }^{\mathrm{b}} \mathrm{M}=\mathrm{Al}$ or $\mathrm{Fe}$.

${ }^{\mathrm{c}}$ Determined by EDX.

SDT Q600 V8.1 Build 99. The characterization was performed at a heating rate of $10^{\circ} \mathrm{C} / \mathrm{min}$ in the range of temperature $=$ $30-600^{\circ} \mathrm{C}$. The crystallinity of polymers was calculated by the following equation:

$$
\chi_{c}=\left[\frac{\Delta H}{\left(\Delta H^{\circ}\right)}\right] \times 100
$$

where $\Delta H$ is heat of fusion of polyethylene sample.

$\Delta H^{\circ}$ is that the heat of fusion of linear polyethylene equals to $290 \mathrm{~J} / \mathrm{g}$ [16].

\section{Results and Discussion}

3.1. Catalyst Characterization. Table 2 reported the chemical compositions of all catalysts determined by ICP and EDX measurements. It was found that although the addition of $\mathrm{TiCl}_{4}$ amount of all catalysts was fixed, the titanium contents in bulk, which were determined by ICP, were slightly changed compared with None-THF due to the presence of different Lewis acids on the support. This might be the fact that the Lewis acid modification can reduce free-vacancies of $\mathrm{MgCl}_{2}$ crystallization and $\mathrm{Ti}$ insertion $[17,18]$. Thus, the titanium content of Al-THF slightly decreased. According to this result, it is also in good agreement with the report by Coutinho and Xavier [19]. They observed that the addition of $\mathrm{PCl}_{3}$ in $\mathrm{TiCl}_{4} / \mathrm{MgCl}_{2}$ via ball milling method decreased the $\mathrm{Ti}$ incorporation due to decrease of free-chloride crystal vacancies in the surface of milled $\mathrm{MgCl}_{2}$ caused by the complexation of $\mathrm{PCl}_{3}$. Furthermore, increasing of $\mathrm{PCl}_{3}$ content can be attributed to the reduction of catalyst active sites resulting in drop in $\mathrm{Ti}$ incorporation. Nonetheless, $\mathrm{Ti}$ content in bulk of Fe-THF increased compared with NoneTHF. This is because the radius of iron (II) ions $\left(\mathrm{Fe}^{2+}\right)$ and the crystal compound structures $\left(\mathrm{FeCl}_{2}\right)$ were similar to $\mathrm{Mg}^{2+}$ and $\mathrm{MgCl}_{2}$. Moreover, Tanase et al. [20] reported that the catalyst contained metal dichloride as a carrier material exhibited relatively high activity compared with $\mathrm{MgCl}_{2}$. Therefore, $\mathrm{FeCl}_{2}$ was considered as one of effective supports for anchoring $\mathrm{TiCl}_{4}$ resulting in the improvement of $\mathrm{Ti}$ content. However, from the EDX result, it was found that all catalysts showed higher Ti content on catalyst surface than Ti content measured by ICP technique. This indicated that most Ti active sites were located on the surface of catalyst more than in the catalyst pores. In addition, the Lewis acid contained catalysts showed a higher $\mathrm{Ti} / \mathrm{Mg}$ ratio than that of unmodified catalyst. Fe-THF displays the highest $\mathrm{Ti} / \mathrm{Mg}$ ratio. It indicated that a lot of $\mathrm{Ti}$ atoms can incorporate at $\mathrm{MgCl}_{2}$ support.

3.1.1. FT-IR Spectroscopy of Catalysts. FT-IR spectroscopy was applied to define the interaction of $\mathrm{TiCl}_{4}$ and $\mathrm{MgCl}_{2}$ support as presented in Figure 1. Typically, IR spectra of the $\mathrm{TiCl}_{4} / \mathrm{MgCl}_{2}$ complex with THF were in the range of $1100-$ $700 \mathrm{~cm}^{-1}$, indicating the most sensitive to THF complexes with a metal center [21]. Many researchers reported that pure THF shows the symmetrical and asymmetrical C-O-C stretching bands around $913 \mathrm{~cm}^{-1}$ and $1071 \mathrm{~cm}^{-1}$, respectively $[21,22]$. However, $\mathrm{TiCl}_{4} / \mathrm{MgCl}_{2} / \mathrm{THF}$ catalysts modified with different Lewis acids (Al-THF and Fe-THF) exhibited a slight shift to the lower wavenumbers compared with None-THF. None-THF, Al-THF, and Fe-THF display the symmetrical C$\mathrm{O}-\mathrm{C}$ stretching bands at $883.4,874.6$, and 873.6 , respectively, and its asymmetrical C-O-C stretching bands at 1032.6, 1025.1, and 1024.6, respectively. It indicated that metal halides incorporated with the Ti-Mg-THF bimetallic complex resulting in the lower frequencies of the C-O-C stretching bands of THF. Therefore, this result may cause an increase in the Lewis acidity of the active center $[2,3]$. All catalysts also displayed $\mathrm{C}-\mathrm{H}$ stretching band around $2885-2976 \mathrm{~cm}^{-1}$. In addition, a neutral alkoxy $\mathrm{Ti}$ species, which are inactive, via the ringopening of THF were also found [1]. These IR spectra were observed in the range of $3000-3600 \mathrm{~cm}^{-1}$. These results are probably due to the fact that the interaction of $\mathrm{MgCl}_{2}$ and THF can change the nature of Ti species through creating a transient cationic Ti mononuclear species, which finally leads to a neutral alkoxy Ti species via the ring-opening of THF [1].

3.1.2. XRD Measurement of Catalysts. XRD patterns of synthesized catalysts are reported in Figure 2. The peaks at $2 \theta=$ $14.9^{\circ}, 30.2^{\circ}, 34.8^{\circ}$, and $50.3^{\circ}$ represent the high disorders of $\delta$ form of $\mathrm{MgCl}_{2}$ species, which are active for polymerization. The characteristic peaks of $\mathrm{MgCl}_{2} / \mathrm{THF}$ complex were located at $2 \theta=20.4^{\circ}$ and $32.0^{\circ}[16,17]$. The XRD peak around $2 \theta=18.1^{\circ}$ was also found and assigned as the creation of $\mathrm{TiCl}_{4} / \mathrm{MgCl}_{2} / \mathrm{THF}$ complex [23]. Moreover, the characteristic peaks of $\mathrm{TiCl}_{4} / \mathrm{THF}$ complex and $\mathrm{TiCl}_{3} / \mathrm{THF}$ complex were noticed at $2 \theta=11.1^{\circ}$ and $17.8^{\circ}$, respectively $[16,17,23]$. We did not observe the Lewis acid characteristic peak of Lewis acid 


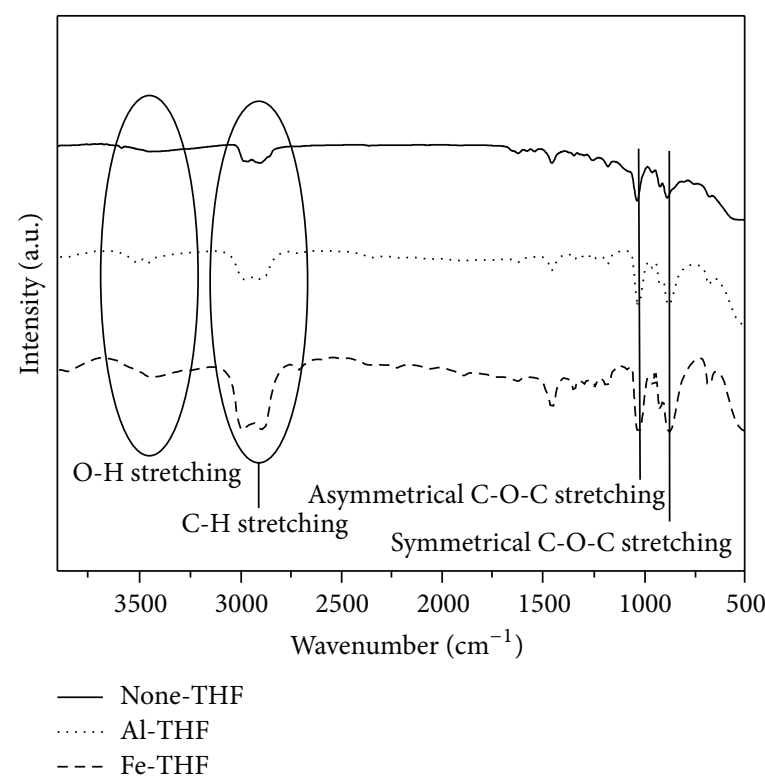

(a)

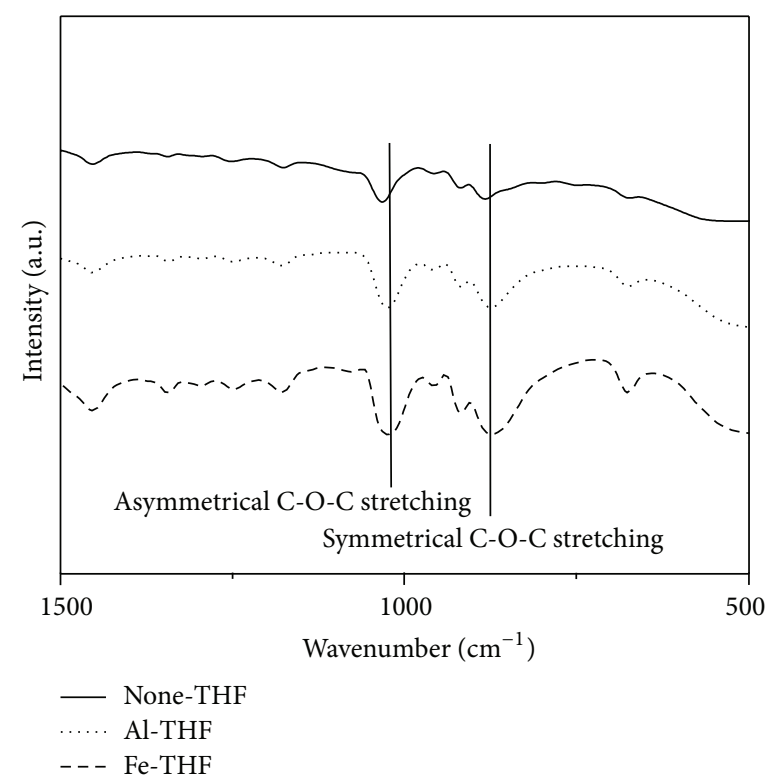

(b)

FIGURE 1: FT-IR spectra of catalysts: in the range of $500-3900 \mathrm{~cm}^{-1}$ (a), extend in the range of $500-1500 \mathrm{~cm}^{-1}(\mathrm{~b})$.

modified catalysts because Lewis acid completely participated in $\mathrm{TiCl}_{4} / \mathrm{MgCl}_{2} / \mathrm{THF}$ structure $[24,25]$. It can be suggested that the radius of $\mathrm{Fe}^{2+}(0.61 \AA)$ is closer to $\mathrm{Mg}^{2+}(0.65 \AA)$ than that of $\mathrm{Al}^{3+}(0.50 \AA)$. Thus, the compatibility of $\mathrm{FeCl}_{2}$ with $\mathrm{MgCl}_{2}$ would be better than that of $\mathrm{AlCl}_{3}$ with $\mathrm{MgCl}_{2}$ $[16,26]$. Due to the fact that Lewis acid can remove THF from $\mathrm{MgCl}_{2} / \mathrm{THF}$ complex, therefore, Lewis acid presumably destroys the crystalline structure of $\mathrm{MgCl}_{2} / \mathrm{THF}$ complex. This results in the lowering or loss in magnitude of XRD peaks at $2 \theta=20.4^{\circ}$ and $32.0^{\circ}$.

3.1.3. SEM Images of Catalysts. Typical SEM images are shown in Figure 3. It can be seen that None-THF is in irregular shape while modified catalysts with Lewis acid (AlTHF and Fe-THF) are in shape of bar.

\subsection{Catalytic Activity}

3.2.1. Effect of Lewis Acids Modification on the Catalytic Activity in the Absence of Hydrogen. According to Table 3, Lewis acid modification by adding $\mathrm{AlCl}_{3}$ and $\mathrm{FeCl}_{2}$ can improve the activity around $17 \%$ and $86 \%$ increase, respectively, compared with the activity of unmodified catalyst. This is because of the formation of acidic sites by modifying the catalysts with Lewis acids [2]. In addition, $\mathrm{AlCl}_{3}$ and $\mathrm{FeCl}_{2}$ could also remove THF in catalyst resulting in enhancement in the activity of ethylene polymerization. The remaining THF of $\mathrm{MgCl}_{2}$. THF structure in the final catalyst leads to the reduction in catalytic activity because the remaining THF can poison the catalyst active sites [5]. THF occupies the coordination sites of $\mathrm{Ti}$ to make Ti a neutral alkoxy $\mathrm{Ti}$ species, which is an inactive center, via the ring-opening of THF [1]. Moreover, TEA can also coordinate with THF and remove some THF from the

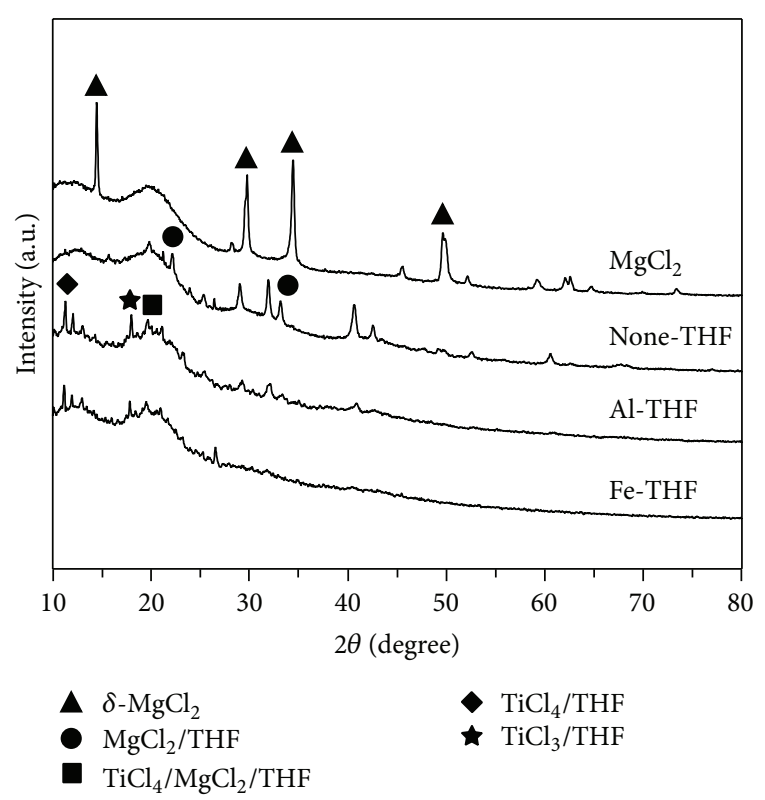

FIGURE 2: XRD patterns of prepared catalysts.

Ti center and then provide higher catalytic activity [5]. Chen and Fan [27] stated that the active center distribution of $\mathrm{TiCl}_{4} / \mathrm{MgCl}_{2}$ could change by doping $\mathrm{AlCl}_{3}$, which can be observed by the polymer GPC curves through multiple Flory components. From the formation of more types of active center, Al-Mg-THF complex [28] leads to an improvement of catalyst performance. As mentioned earlier about the similar ionic radii of $\mathrm{Fe}$ and $\mathrm{Mg}$, it could then be stated that $\mathrm{FeCl}_{2}$ was more efficient to incorporate with $\mathrm{MgCl}_{2}$ than $\mathrm{AlCl}_{3}$. Therefore, Fe-THF gave higher activity than Al-THF. 


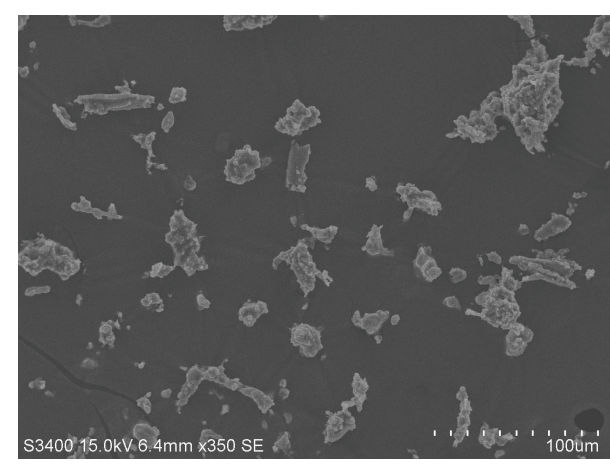

(a)

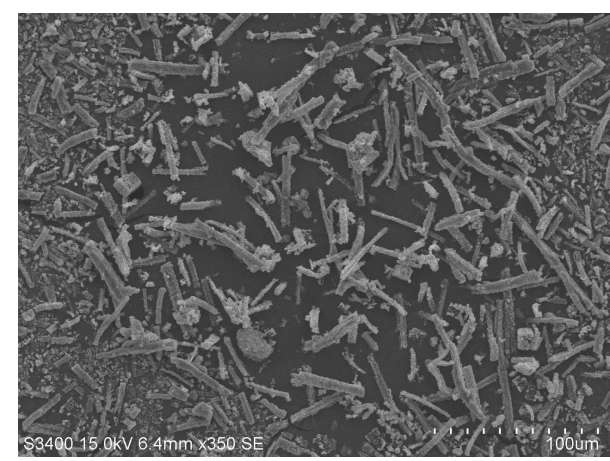

(c)

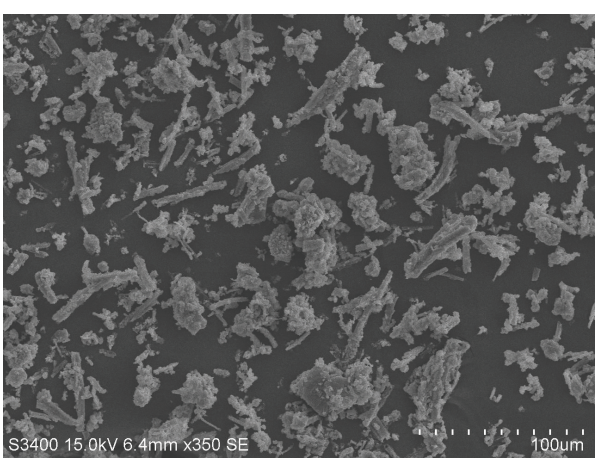

(e)

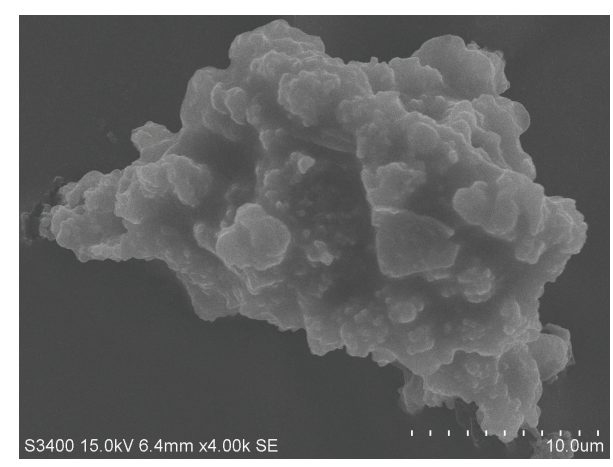

(b)

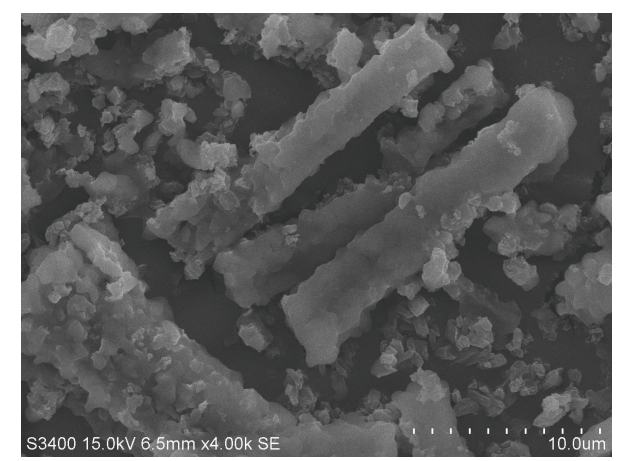

(d)

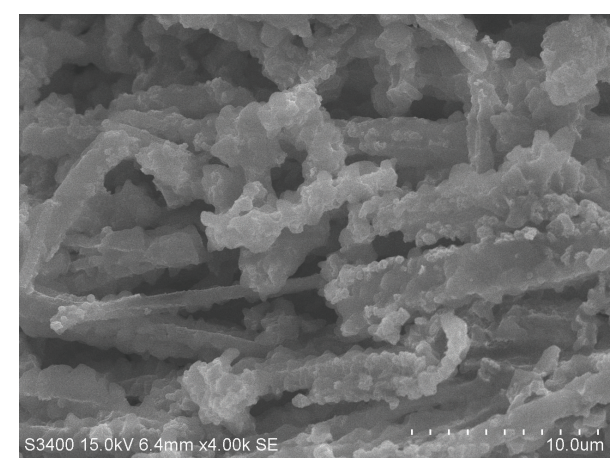

(f)

FIGURE 3: SEM images of prepared catalysts: ((a), (b)) None-THF, ((c), (d)) Al-THF, and ((e), (f)) Fe-THF.

3.2.2. Effect of Lewis Acids Modification on Hydrogen Response for Ethylene Polymerization. $\mathrm{TiCl}_{4} / \mathrm{MgCl}_{2} / \mathrm{THF}$ catalysts modified with Lewis acids $\left(\mathrm{AlCl}_{3}\right.$ and $\left.\mathrm{FeCl}_{2}\right)$ were conducted in ethylene polymerization in the presence of various hydrogen pressures for comparative study on catalytic activities. The polymerization activities results of $\mathrm{TiCl}_{4} /$ Lewis acid $/ \mathrm{MgCl}_{2} / \mathrm{THF}$ catalysts are summarized in Table 3 . Catalysts modified with Lewis acid presented the higher hydrogen response than unmodified catalyst, especially Fe-THF. Hydrogen response is high even in the system that has a small amount of hydrogen. Only small additional amount of hydrogen at $\mathrm{H}_{2} / \mathrm{C}_{2} \mathrm{H}_{4}$ molar ratio of 0.08 results in $34 \%$ decrease in activity for Al-THF and $67 \%$ decrease in activity for Fe-THF. This indicates high hydrogen response for these catalysts in this $\mathrm{H}_{2} / \mathrm{C}_{2} \mathrm{H}_{4}$ molar ratio period. From these results, this is probably due to increasing in acidic sites [2] by doping Lewis acid. Therefore, addition of Lewis acid causes the formation of more clustered active center leading to obtaining more chances to proceed chain transfer reaction by hydrogen. This result is in good agreement with article reported by Kouzai et al. [29]. They revealed that chain transfer reactions by hydrogen will occur when hydrogen dissociation sites are located in the instant surrounding of polymerization sites. Thus, the more the clustered active species, the higher the hydrogen response. In part of higher hydrogen amount at $\mathrm{H}_{2} / \mathrm{C}_{2} \mathrm{H}_{4}$ molar ratio of $0.2-0.3$, the increment of hydrogen pressure in the system was conducted. Activity of all catalysts did not change much compared with its activity in the less-hydrogen system $\left(\mathrm{H}_{2} / \mathrm{C}_{2} \mathrm{H}_{4}\right.$ molar ratio of 0.08 ). It could be implied that most of active sites were deactivated by hydrogen. The reason is that the creation of titanium-hydride bond, which is less active, was higher. 


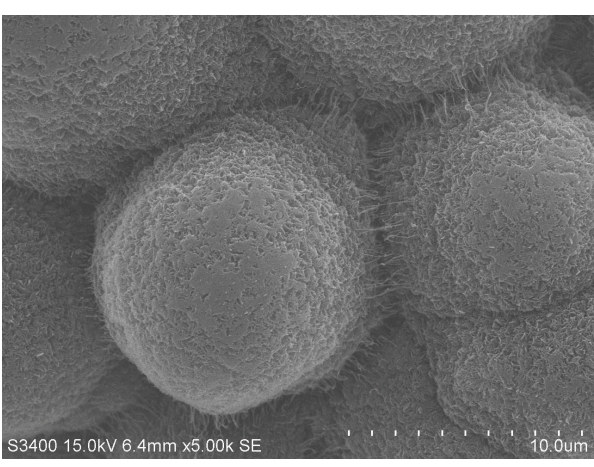

(a)

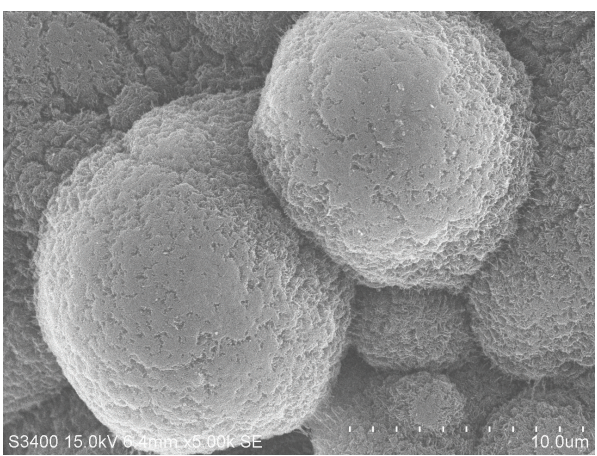

(c)

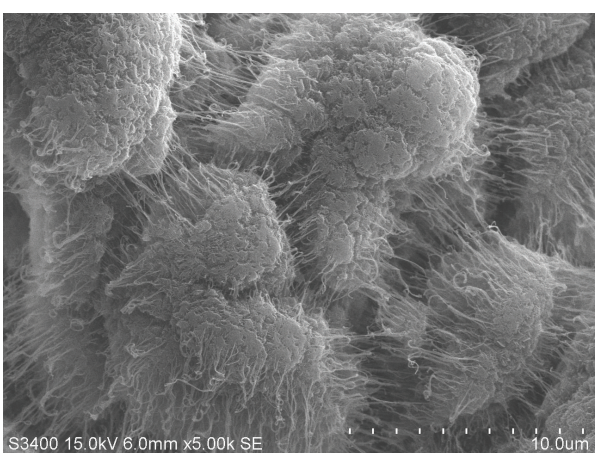

(e)

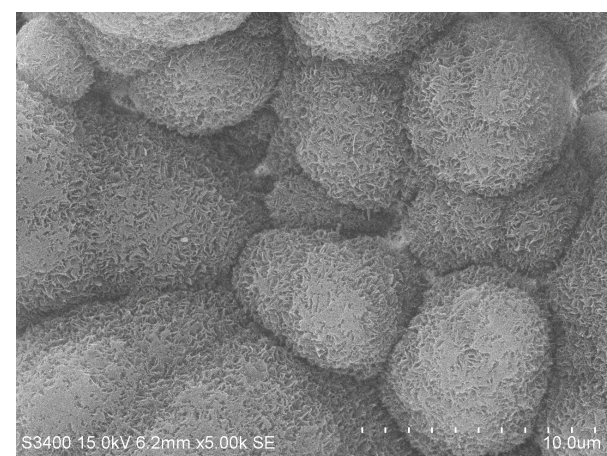

(b)

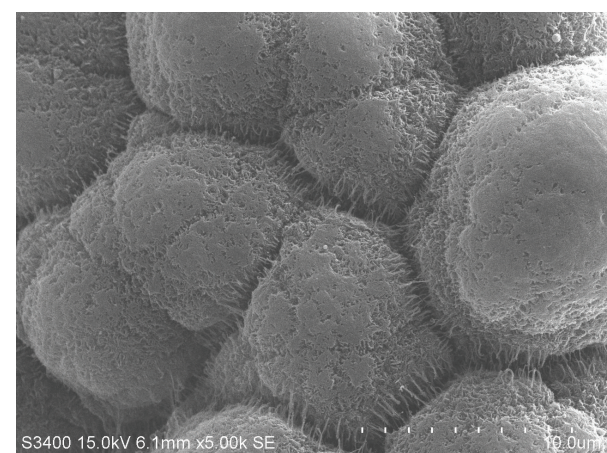

(d)

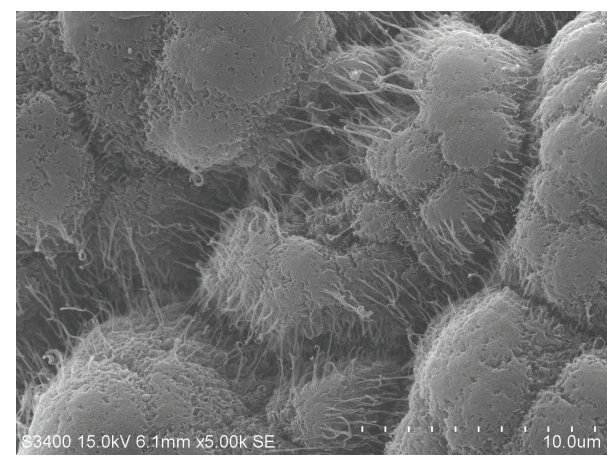

(f)

Figure 4: SEM images of the polyethylene obtained by (a) None-THF, (c) Al-THF, and (e) Fe-THF in the absence of $\mathrm{H}_{2}$ and (b) None-THF, (d) Al-THF, and (f) Fe-THF at $\mathrm{H}_{2} / \mathrm{C}_{2} \mathrm{H}_{4}$ molar ratio $=0.30$.

Moreover, only the uncoordinated $\mathrm{Ti}-\mathrm{C}_{2} \mathrm{H}_{5}$ bond is capable of reaction with ethylene monomer to generate the chain growth reaction [30-32]. This results in the reduction in activity and lower hydrogen response. Fe-THF is considered as a more clustered catalyst than Al-THF because it has higher Ti content than Al-THF. Moreover, catalyst having less titanium content, Al-THF, exhibited a less deactivation effect than the catalyst having higher titanium content, Fe-THF, due to the less amount of surface active site being able to react with TEA. Therefore, Fe-THF indicated the higher hydrogen response which showed rapidly dropped activity than AlTHF. However, a higher Ti content has a higher stereospecificity than a lower Ti content forming an isolated Ti site [29, $33,34]$. As a consequence, one of the possible reasons was the aggregation of Ti species which caused the reduction of active site concentration, resulting in remarkable depression of the monomer consumption [33] and finally decrease in activity. This result is in good agreement with the report of Taniike et al. [33]. They investigated the catalytic performance through the isolated and clustered Zeigler-Natta catalysts in ethylene and propylene homopolymerization. They also found that the isolated Ti species located on the $\mathrm{MgCl}_{2}$ surface which acted as the loss of $\mathrm{Ti}-\mathrm{Ti}$ interaction led to higher activity in both ethylene and propylene polymerization with $\mathrm{TiCl}_{3} / \mathrm{MgCl}_{2}$ model catalyst.

3.3. Polymer Characterization. The morphologies of obtained polyethylene are shown in Figure 4. It could be reported that all catalysts, including with and without Lewis acid modification, provided the similar morphology of polymer. 
TABLE 3: Catalytic activity of different doped Lewis acid catalysts in ethylene polymerization.

\begin{tabular}{|c|c|c|c|c|}
\hline Catalyst & $\begin{array}{c}\mathrm{H}_{2} / \mathrm{C}_{2} \mathrm{H}_{4} \text { molar } \\
\text { ratio } \\
\end{array}$ & $\begin{array}{c}\text { Activity }^{\mathrm{a}} \\
(\mathrm{kg} \mathrm{PE} / \mathrm{gTi} * \mathrm{~h}) \\
\end{array}$ & $\begin{array}{c}\text { Activity ratio without } \\
\qquad \mathrm{H}_{2}\end{array}$ & Activity ratio with $\mathrm{H}_{2}$ \\
\hline \multirow{4}{*}{ None-THF } & 0 & 732 & 1.00 & 1.00 \\
\hline & 0.08 & 645 & - & 0.88 \\
\hline & 0.20 & 362 & - & 0.49 \\
\hline & 0.30 & 313 & - & 0.43 \\
\hline \multirow{4}{*}{ Al-THF } & 0 & 854 & 1.17 & 1.00 \\
\hline & 0.08 & 560 & - & 0.66 \\
\hline & 0.20 & 279 & - & 0.33 \\
\hline & 0.30 & 246 & - & 0.29 \\
\hline \multirow{4}{*}{ Fe-THF } & 0 & 1364 & 1.86 & 1.00 \\
\hline & 0.08 & 452 & - & 0.33 \\
\hline & 0.20 & 330 & - & 0.24 \\
\hline & 0.30 & 375 & - & 0.28 \\
\hline
\end{tabular}

${ }^{a}$ Condition: polymerization was performed in $2 \mathrm{~L}$ autoclave, $[\mathrm{Ti}]=0.008 \mathrm{mmol}$ for all catalysts, $\mathrm{Al} / \mathrm{Ti}$ molar ratio $=140$, cocatalyst $=\mathrm{TEA}$, polymerization time $=1 \mathrm{~h}$, reaction temperature $=80^{\circ} \mathrm{C}$, total pressure $=8$ bars under 1 bar of nitrogen, and desired amount of $\mathrm{H}_{2} / \mathrm{C}_{2} \mathrm{H}_{4}$ molar ratio $=0,0.08,0.20$, and 0.30 .

TABLE 4: Influences of Lewis acids and hydrogen on polyethylene.

\begin{tabular}{|c|c|c|c|c|c|c|}
\hline Catalyst & $\begin{array}{c}\mathrm{H}_{2} / \mathrm{C}_{2} \mathrm{H}_{4} \text { molar } \\
\text { ratio } \\
\end{array}$ & $\begin{array}{c}\text { Melting temperature } \\
\left(T_{m}\right) \text { in }{ }^{\circ} \mathrm{C}\end{array}$ & $\begin{array}{l}\text { Crystallinity }^{\mathrm{a}} \\
\left(\chi_{c}\right) \text { in } \%\end{array}$ & $\begin{array}{c}\mathrm{Mw}^{\mathrm{b}} \\
(\mathrm{g} / \mathrm{mol})\end{array}$ & $\begin{array}{c}\mathrm{Mn}^{\mathrm{b}} \\
(\mathrm{g} / \mathrm{mol})\end{array}$ & $\mathrm{Mw} / \mathrm{Mn}^{\mathrm{b}}$ \\
\hline \multirow{4}{*}{ None-THF } & 0 & 132.9 & 55.4 & - & - & - \\
\hline & 0.08 & 131.2 & 58.0 & 452,127 & 74,155 & 6.1 \\
\hline & 0.20 & 129.8 & 59.7 & 249,214 & 40,292 & 6.2 \\
\hline & 0.30 & 129.0 & 56.2 & 178,786 & 31,277 & 5.7 \\
\hline \multirow{4}{*}{ Al-THF } & 0 & 133.8 & 54.7 & - & - & - \\
\hline & 0.08 & 131.2 & 60.7 & 335,552 & 53810 & 6.2 \\
\hline & 0.20 & 130.0 & 60.1 & 204,614 & 35,852 & 5.7 \\
\hline & 0.30 & 130.1 & 68.5 & 189,568 & 33,557 & 5.7 \\
\hline \multirow{4}{*}{ Fe-THF } & 0 & 134.2 & 52.8 & - & - & - \\
\hline & 0.08 & 131.9 & 55.7 & 370,021 & 56,998 & 6.5 \\
\hline & 0.20 & 130.0 & 66.8 & 230,272 & 35,756 & 6.4 \\
\hline & 0.30 & 130.0 & 62.8 & 201,312 & 29,107 & 6.9 \\
\hline
\end{tabular}

${ }^{\mathrm{a}}$ Determined by DSC.

${ }^{\mathrm{b}}$ Determined by GPC.

Condition: polymerization was performed in $2 \mathrm{~L}$ autoclave, $[\mathrm{Ti}]=0.008 \mathrm{mmol}$ for all catalysts, $\mathrm{Al} / \mathrm{Ti}$ molar ratio $=140$, cocatalyst $=\mathrm{TEA}$, polymerization time $=1 \mathrm{~h}$, reaction temperature $=80^{\circ} \mathrm{C}$, total pressure $=8$ bars under 1 bar of nitrogen, and desired amount of $\mathrm{H}_{2} / \mathrm{C}_{2} \mathrm{H}_{4}$ molar ratio $=0,0.08,0.20$, and 0.30 .

Not only in the absence of hydrogen case, but also in the presence of hydrogen, the morphologies of resultant polymer were also similar.

\subsubsection{Effect of Lewis Acids Modification on Polyethylene} Properties. According to Table 4, polymers producing from Al-THF and Fe-THF without additional hydrogen exhibited a slight increase in melting temperature, but Lewis acid modification (Al-THF and Fe-THF) decreases crystallinity when compared with None-THF. These are the results from utilizing of the different types of Lewis acids. All catalysts produce polymers having the similar $\mathrm{Mw} / \mathrm{Mn}$, which are quite narrow Mw/Mn. This is because the doped and undoped catalysts had basically the same types of active sites [26].

3.3.2. Effect of Hydrogen on Polyethylene Properties. As presented in Table 4, the molecular weight of polymer decreased when hydrogen increased because chain termination reaction by hydrogen occurred. As a consequence, the melting temperature decreases due to the decrease in molecular weight of polyethylenes. In addition, the increase in hydrogen pressure tends to increase the crystallinity of all polymers [8]. This is because the polymerization rate is reduced by hydrogen resulting in increase in crystallization rate [8]. Mw/Mn of 
all polymers did not change much at the different levels of hydrogen. This result is in agreement with that of Li Pi Shan et al. [13].

\section{Conclusion}

In conclusion, Lewis acid modification by using metal halide $\left(\mathrm{AlCl}_{3}\right.$ and $\left.\mathrm{FeCl}_{2}\right)$ can improve activity due to the formation of acidic sites and the elimination of the remaining THF in the final catalyst as proven by XRD. In addition, $\mathrm{FeCl}_{2}$ showed higher efficiency to remove the remaining THF in $\mathrm{MgCl}_{2}$ structure than $\mathrm{AlCl}_{3}$. Thus, the activity was in the order of Fe$\mathrm{THF}>\mathrm{Al}-\mathrm{THF}>\mathrm{None}-\mathrm{THF}$. In the presence of hydrogen, $\mathrm{Fe}-$ THF is considered to have more clustered Ti species than AlTHF. Therefore, Fe-THF showed a higher hydrogen response than Al-THF due to the titanium distribution. The increase in hydrogen results in the decrease in melting temperature, but it tends to increase the crystallinity of all polymers.

\section{Additional Points}

Research Highlights. (i) Active center distribution has a strong effect on $\mathrm{TiCl}_{4} / \mathrm{MgCl}_{2} / \mathrm{THF}$ performances. (ii) The study on the active center distribution has not been yet clarified because of the limitation of characterization apparatus. (iii) Hydrogen response is considered to be one of the most effective ways to describe how the active sites dispersed in Ziegler-Natta catalysts. (iv) Lewis acid modification can improve activity due to the formation of acidic sites and removing the remaining $\mathrm{THF}$ in the catalyst. (v) Fe-THF is considered as a more clustered $\mathrm{Ti}$ species than Al-THF. (vi) $\mathrm{FeCl}_{2}$-doped catalyst showed a higher hydrogen response than $\mathrm{AlCl}_{3}$ doped catalyst due to its Ti distribution.

\section{Competing Interests}

The authors declare that there are no competing interests regarding the publication of this paper.

\section{Acknowledgments}

This research was funded by the Royal Golden Jubilee Ph.D. scholarship from Thailand Research Fund (PHD/0236/2553) and the Ratchadapisek Sompoch Endowment Fund (2015), Chulalongkorn University (CU-58-027-AM). The authors gratefully thank Thai Polyethylene Co., Ltd., for GPC measurement.

\section{References}

[1] E. Grau, A. Lesage, S. Norsic, C. Copéret, V. Monteil, and P. Sautet, "Tetrahydrofuran in $\mathrm{TiCl}_{4} / \mathrm{THF} / \mathrm{MgCl}_{2}$ : a non-innocent ligand for supported Ziegler-Natta polymerization catalysts," ACS Catalysis, vol. 3, no. 1, pp. 52-56, 2013.

[2] W. Phiwkliang, B. Jongsomjit, and P. Praserthdam, "Synergistic effects of the $\mathrm{ZnCl}_{2}-\mathrm{SiCl}_{4}$ modified $\mathrm{TiCl}_{4} / \mathrm{MgCl}_{2} / \mathrm{THF}$ catalytic system on ethylene/1-hexene and ethylene/1-octene copolymerizations," Chinese Journal of Polymer Science, vol. 32, no. 1, pp. 84-91, 2014.
[3] K.-J. Chu, H.-S. Chang, and S.-K. Ihm, "Effects of diethyl aluminum chloride (DEAC) addition to the catalysts prepared by reduction of $\mathrm{TiCl}_{4}$ with $\mathrm{EtMgCl}$ on ethylene-propylene copolymerization," European Polymer Journal, vol. 30, no. 12, pp. 1467-1472, 1994.

[4] K. Bosowska and M. Nowakowska, "The roles for a Lewis base and $\mathrm{MgCl}_{2}$ in third-generation Ziegler-Natta catalysts," Journal of Applied Polymer Science, vol. 69, no. 5, pp. 1005-1011, 1998.

[5] H. Luo, R.-G. Tang, and K.-J. Gao, "Studies on the formation of new, highly active silica-supported ziegler-natta catalyst for ethylene Polymerization," Journal of Catalysis, vol. 210, no. 2, pp. 328-339, 2002.

[6] S. Pirinen, I. O. Koshevoy, P. Denifl, and T. T. Pakkanen, "A single-crystal model for $\mathrm{MgCl}_{2}$-electron donor support materials: $\left[\mathrm{Mg}_{3} \mathrm{Cl}_{5}(\mathrm{THF})_{4} \mathrm{Bu}\right]_{2}(\mathrm{Bu}=\mathrm{n}$-Butyl)," Organometallics, vol. 32, no. 15, pp. 4208-4213, 2013.

[7] P. Sobota, "Metal-assembled compounds: precursors of polymerization catalysts and new materials," Coordination Chemistry Reviews, vol. 248, no. 11-12, pp. 1047-1060, 2004.

[8] M. A. Parvez, M. Rahaman, M. A. Suleiman, J. B. P. Soares, and I. A. Hussein, "Correlation of polymerization conditions with thermal and mechanical properties of polyethylenes made with Ziegler-Natta catalysts," International Journal of Polymer Science, vol. 2014, Article ID 549031, 10 pages, 2014.

[9] M. Rahaman, M. A. Parvez, J. B. P. Soares, and I. A. Hussein, "Effect of polymerization conditions on thermal and mechanical properties of ethylene/1-butene copolymer made with Ziegler-Natta catalysts," International Journal of Polymer Science, vol. 2014, Article ID 654260, 10 pages, 2014.

[10] M. L. Méndez-Hernández, J. L. Rivera-Armenta, U. PáramoGarcía, S. Corona Galvan, R. García-Alamilla, and B. A. SalazarCruz, "Synthesis of high cis-1,4-BR with neodymium for the manufacture of tires," International Journal of Polymer Science, vol. 2016, Article ID 7239540, 7 pages, 2016.

[11] P. Panupakorn, E. Chaichana, P. Praserthdam, and B. Jongsomjit, "Polyethylene/clay nanocomposites produced by in situ polymerization with zirconocene/MAO catalyst," Journal of Nanomaterials, vol. 2013, Article ID 154874, 9 pages, 2013.

[12] M. A.-H. Ali, J. Stroomer, B. Betlem, G. Weickert, and B. Roffel, "Molecular weight distribution broadening of polypropylene by periodic switching of hydrogen and catalyst additions," Journal of Applied Polymer Science, vol. 108, no. 4, pp. 2446-2457, 2008.

[13] C. Li Pi Shan, J. B. P. Soares, and A. Penlidis, "Ethylene/1-octene copolymerization studies with in situ supported metallocene catalysts: effect of polymerization parameters on the catalyst activity and polymer microstructure," Journal of Polymer Science Part A: Polymer Chemistry, vol. 40, no. 24, pp. 4426-4451, 2002.

[14] M. C. Sacchi, F. Forlini, I. Tritto et al., "Polymerization stereochemistry with Ziegler-Natta catalysts containing dialkylpropane diethers: a tool for understanding internal/external donor relationships," Macromolecules, vol. 29, no. 10, pp. 33413345, 1996.

[15] M. L. Hair and W. Hertl, "Reaction of hexamethyldisilazane with silica," The Journal of Physical Chemistry, vol. 75, no. 14, pp. 2181-2185, 1971.

[16] W. Phiwkliang, B. Jongsomjit, and P. Praserthdam, "Effect of $\mathrm{ZnCl}_{2}$ - and $\mathrm{SiCl}_{4}$-doped $\mathrm{TiCl}_{4} / \mathrm{MgCl}_{2} / \mathrm{THF}$ catalysts for ethylene polymerization," Journal of Applied Polymer Science, vol. 130, no. 3, pp. 1588-1594, 2013. 
[17] H.-S. Chang, W.-D. Song, K.-J. Chu, and S.-K. Ihm, "Effects of removing THF from the $\mathrm{TiCl}_{3}(\mathrm{AA}) /{ }_{3} \mathrm{MgCl}_{2} / \mathrm{THF}$ catalyst system on the ethylene-propylene copolymerization mechanism," Macromolecules, vol. 25, no. 8, pp. 2086-2092, 1992.

[18] W. Wang, L. Wang, T. Chen, T. X. Sun, J. J. Wang, and X. Chen, "Low isotactic polypropylene synthesized with a $\mathrm{MgCl}_{2} / \mathrm{AlCl}_{3}$ supported Ziegler catalyst," Journal of Molecular Catalysis A: Chemical, vol. 244, no. 1-2, pp. 146-150, 2006.

[19] F. M. B. Coutinho and J. L. L. Xavier, "Properties of ethylenepropylene copolymers synthesized by a supported ZieglerNatta catalyst based on $\mathrm{TiCl}_{4} / \mathrm{MgCl}_{2} / \mathrm{PCl}_{3}$," European Polymer Journal, vol. 33, no. 6, pp. 897-901, 1997.

[20] S. Tanase, K. Katayama, S. Inasawa et al., "New synthesis method using magnesium alkoxides as carrier materials for Ziegler-Natta catalysts with spherical morphology," Macromolecular Reaction Engineering, vol. 2, no. 3, pp. 233-239, 2008.

[21] J. H. Kim, T. K. Han, H. K. Choi, I. Kim, and S. I. Woo, "Copolymerization of ethylene and 1-butene with highly active TI/MG bimetallic catalysts. Effect of partial activation by $\mathrm{AlEt}_{2} \mathrm{Cl}$," Macromolecular Rapid Communications, vol. 16, no. 2, pp. 113-118, 1995.

[22] S. Pirinen and T. T. Pakkanen, "Polyethers as potential electron donors for Ziegler-Natta ethylene polymerization catalysts," Journal of Molecular Catalysis A: Chemical, vol. 398, pp. 177-183, 2015.

[23] K. Seenivasan, A. Sommazzi, F. Bonino, S. Bordiga, and E. Groppo, "Spectroscopic investigation of heterogeneous Ziegler-Natta catalysts: Ti and Mg chloride tetrahydrofuranates, their interaction compound, and the role of the activator," Chemistry-A European Journal, vol. 17, no. 31, pp. 8648-8656, 2011.

[24] M. Wannaborworn and B. Jongsomjit, "Ethylene/1-octene copolymerization over Ga-modified $\mathrm{SiO}_{2}$-supported zirconocene/MMAO catalyst using in situ and ex situ impregnation methods," Iranian Polymer Journal, vol. 18, no. 12, pp. 969-979, 2009.

[25] S. Jiamwijitkul, B. Jongsomjit, and P. Praserthdam, "Effect of boron-modified MCM-41-supported dMMAO/zirconocene catalyst on copolymerization of ethylene/1-octene for LLDPE synthesis," Iranian Polymer Journal, vol. 16, no. 8, pp. 549-559, 2007.

[26] D. Fregonese and S. Bresadola, "Catalytic systems supported on $\mathrm{MgCl}_{2}$ doped with $\mathrm{ZnCl}_{2}$ for olefin polymerization," Journal of Molecular Catalysis A: Chemical, vol. 145, no. 1-2, pp. 265-271, 1999.

[27] Y.-P. Chen and Z.-Q. Fan, "Ethylene/1-hexene copolymerization with $\mathrm{TiCl}_{4} / \mathrm{MgCl}_{2} / \mathrm{AlCl}_{3}$ catalyst in the presence of hydrogen," European Polymer Journal, vol. 42, no. 10, pp. 2441-2449, 2006.

[28] Y.-P. Chen, Z.-Q. Fan, J.-H. Liao, and S.-Q. Liao, "Molecular weight distribution of polyethylene catalyzed by Ziegler-Natta catalyst supported on $\mathrm{MgCl}_{2}$ doped with $\mathrm{AlCl}_{3}$," Journal of Applied Polymer Science, vol. 102, no. 2, pp. 1768-1772, 2006.

[29] I. Kouzai, B. Liu, T. Wada, and M. Terano, "Effects of hydrogen for different stereospecific active sites on ultra low $\mathrm{TiCl}_{3}$ loading supported catalyst," Macromolecular Reaction Engineering, vol. 1, no. 1, pp. 160-164, 2007.

[30] T. Garoff, S. Johansson, K. Pesonen, P. Waldvogel, and D. Lindgren, "Decrease in activity caused by hydrogen in ZieglerNatta ethene polymerisation," European Polymer Journal, vol. 38, no. 1, pp. 121-132, 2002.

[31] Y. V. Kissin, R. I. Mink, T. E. Nowlin, and A. J. Brandolini, "Kinetics and mechanism of ethylene homopolymerization and copolymerization reactions with heterogeneous Ti-based Ziegler-Natta catalysts," Topics in Catalysis, vol. 7, no. 1-4, pp. 69-88, 1999.

[32] K.-J. Chu, J. B. P. Soares, and A. Penlidis, "Effect of hydrogen on ethylene polymerization using in-situ supported metallocene catalysts," Macromolecular Chemistry and Physics, vol. 201, no. 5, pp. 552-557, 2000.

[33] T. Taniike, T. Wada, I. Kouzai, S. Takahashi, and M. Terano, "Role of dispersion state of Ti species in deactivation of $\mathrm{MgCl}_{2}$ supported ziegler-natta catalysts," Macromolecular Research, vol. 18, no. 9, pp. 839-844, 2010.

[34] H. Mori, M. Endo, and M. Terano, "Deviation of hydrogen response during propylene polymerization with various Ziegler-Natta catalysts," Journal of Molecular Catalysis A: Chemical, vol. 145, no. 1-2, pp. 211-220, 1999. 

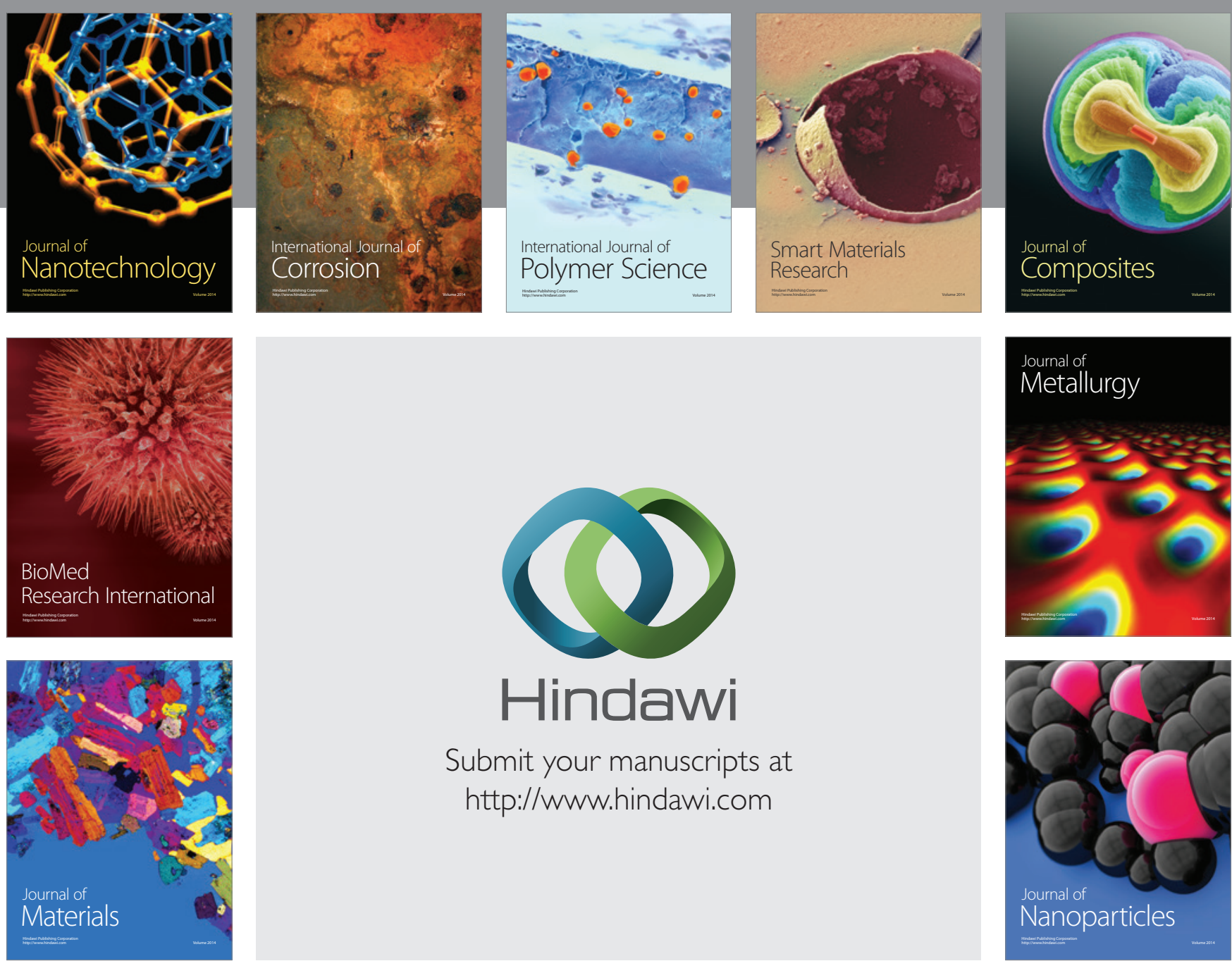

\section{Hindawi}

Submit your manuscripts at

http://www.hindawi.com

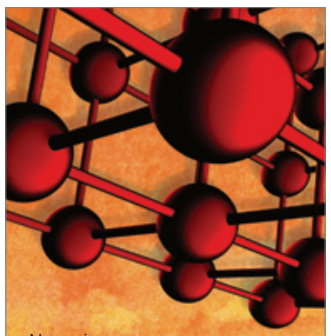

Materials Science and Engineering
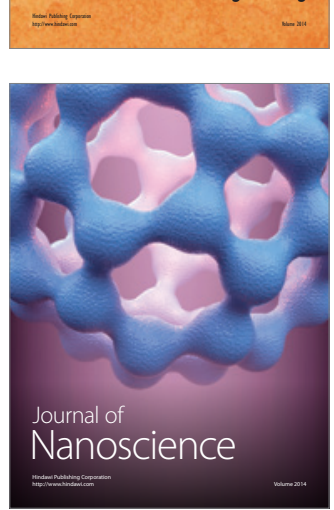
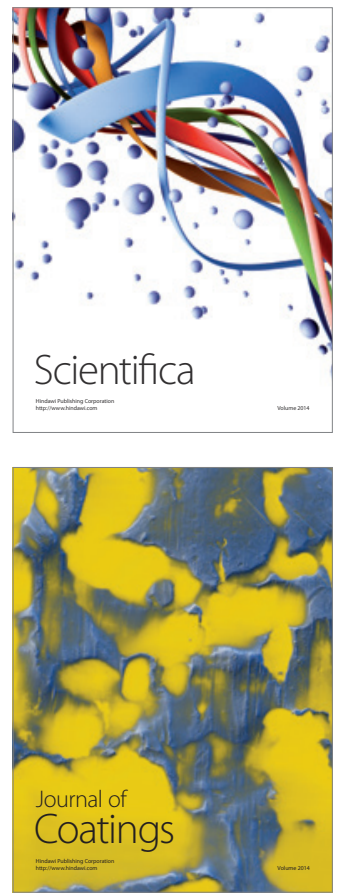
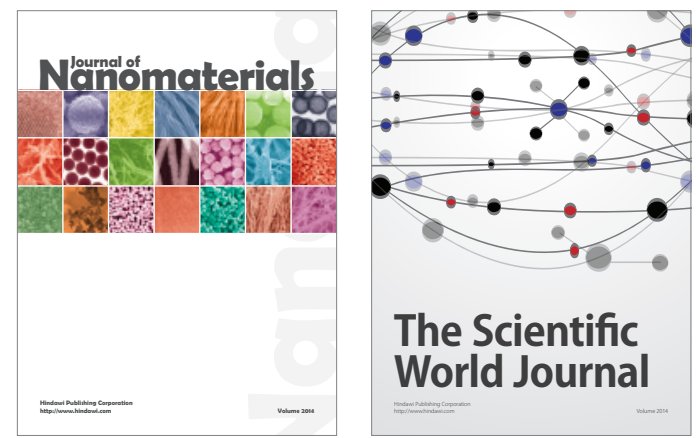

The Scientific World Journal
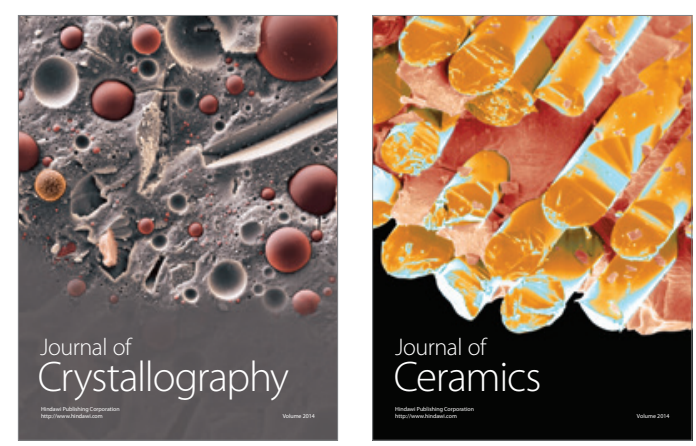
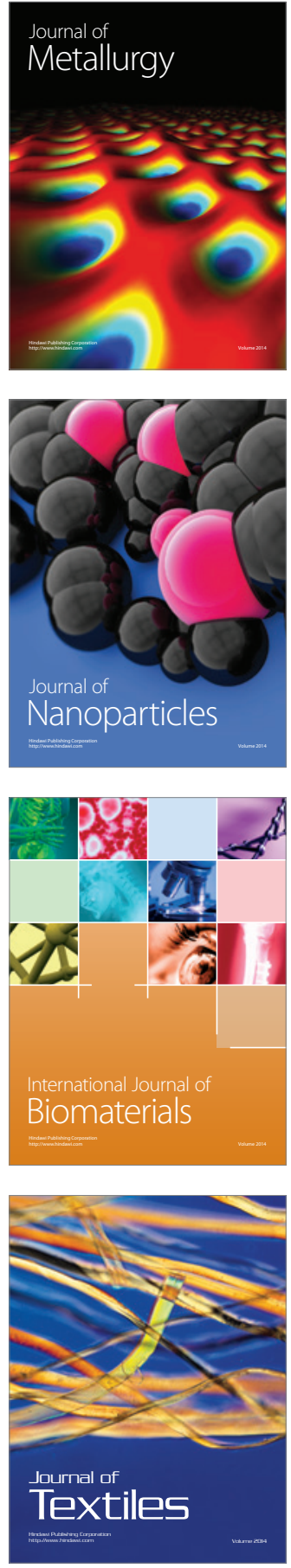